\title{
Application of Supersaturated Design to Study the Spread of Electronic Games
}

\author{
Alanazi Talal Abdulrahman ${ }^{1}$, Randa Alharbi $^{2}$, Osama Alamri $^{2}$, Dalia Alnagar $^{3, *}$, Bader Alruwaili $^{4}$ \\ ${ }^{1}$ Department of Mathematics, University of Ha'il, Saudi Arabia \\ ${ }^{2}$ Department of Statistics, University of Tabuk, Saudi Arabia \\ ${ }^{3}$ Department of Statistics, Omdurman Islamic University, Sudan \\ ${ }^{4}$ Department of Mathematics , Jouf University, Saudi Arabia
}

Received February 27, 2021; Revised April 18, 2021; Accepted April 29, 2021

Cite This Paper in the following Citation Styles

(a): [1] Alanazi Talal Abdulrahman, Randa Alharbi, Osama Alamri, Dalia Alnagar, Bader Alruwaili, "Application of Supersaturated Design to Study the Spread of Electronic Games," Mathematics and Statistics, Vol.9, No.3, pp. 278-284, 2021. DOI: 10.13189/ms.2021.090308.

(b): Alanazi Talal Abdulrahman, Randa Alharbi, Osama Alamri, Dalia Alnagar, Bader Alruwaili, (2021). Application of Supersaturated Design to Study the Spread of Electronic Games. Mathematics and Statistics, 9(3), 278-284. DOI: 10.13189/ms.2021.090308.

Copyright $@ 2021$ by authors, all rights reserved. Authors agree that this article remains permanently open access under the terms of the Creative Commons Attribution License 4.0 International License

\begin{abstract}
A supersaturated design is an important method that relies on factorial designs whose number of factors is greater than experiments' number. The analysis of supersaturated designs is challenging due to the complexity of the design matrix. This problem is challenging due to the fact that the design matrix has a complicated structure. Identification of the variable including the active factor plays an essential role when supersaturated design is used to analyse the data. A variable selection technique to screen active effects in the SSDs and regression analysis are applied to our case study. This study set out to examine the actual reasons for the spread of electronic games statistically such as Saudi society. An online survey provided quantitative data from 200 participants. Respondents were randomly divided into two conditions (Yes+, No-) and asked to respond to one of two sets of the causes of electronic games. The responses was analysed using contrast method with supersaturated designs and regression methods using the SPSS computer software to determine the actual causes that led to the spread of electronic games. The findings i ndicated that b ecause of their constant preoccupation, some parents resort to such games in order to get rid of the child's inconvenience and insufficient awareness among parents of the dangers of these games, and excessive pampering is the factor that led to the spread of electronic games in Saudi society statistically. On this basis, it is recommended that Saudi government professionals develop an operational plan to study these causes to take actions. In future investigations, no recent studies address the external environmental aspects that could influence gaming among individuals, and hence further research is required in this field.
\end{abstract}

Keywords Electronic Games, Supersaturated Designs, Contrast Method, Linear Model, Screening Design, Data Analysis.

\section{Introduction}

Electronic games have spread across all marketplaces and entered all homes, taking over much of children's and adults' time. They have spread very quickly among Arab society in general, and Saudi Arabia in specific. The digital revolution and a availability of internet have been helped spread electronic game.Within the technological revolution in which we are living and the spread of desktop and laptop computers and various smart devices, electronic games have become more present in the our lives. The impact of technology on daily living activities is a significant determinant of the future livelihoods of all individuals worldwide. Gaming has increased among the people of all ages across the world over recent years with an impact by culture. The development of video games continues to grow alongside the Internet expansion. In Saudi Arabia, approximately $63.7 \%$ of the population are internet users, while is more than tenfold higher than in 2001. These days, about 400 dollars spent on electronic games by a Saudi child annually [2]. Both positive and negative outcomes have been attributed to this trend. The spread of electronic games is influenced by diverse factors, including competition for rewards, need for entertainment, motivation and addiction, and its ability to nurture talent and 
develop one's intelligence. An objective of this study is to find the actual causes that led to-electronic games in Saudi society. To achieve this goal, this investigation utilised quantitative data to determine the actual reasons for the spread of electronic games in Saudi society using Supersaturated designs (SSD). This paper begins by the previous research on the spread of electronic games in the country.

Supersaturated design has been widely applied in several studies. The construction of supersaturated designs has been originally proposed by ([12], [4]). An algorithm to construct systematic supersaturated designs suggested by ([12], [4]). Several methods of the construction of supersaturated designs have been widely investigated by ([9], [15], [5], [10] [11] [14]). Some analysis methods were proposed in literature for the analysis of supersaturated designs in recent years. stepwise regression was used to select $p$ active factors by [9]. The identifiability of supersaturated designs was explored by [6]. A Bayesian variable-selection method was suggested by [13]. In addition, [13] proposed forward selection test technique and the effect sparsity hypothesis. The researcher [3] suggested a two-stage Bayesian model selection procedure for supersaturated designs. An approach based on penalised least squares for identifying the active effects in supersaturated designs was proposed [8]. A procedure of finding active factors based on the idea of staged dimensionality reduction was proposed by [11]. A contrast variance approach for analysing data from supersaturated designs was proposed by [7]. The problem of supersaturated designs in identifying the active factors was addressed by [10].

\section{Method}

The aim of this section is to present a procedure for analysing supersaturated designs. In this paper, the linear main effects model is used:

$$
y=x \beta+\epsilon
$$

where $y$ is the vector of $n$ responses from the experiment, $\beta$ is the vector of the $m$ unknown coefficients, $X$ is the $n * m$ design matrix, and is the random error vector with $\left(\epsilon_{1}, \epsilon_{2}, \cdots\right)$ and $\epsilon \sim N\left(0, \sigma^{2}\right)$, for $i=1,2$, Before present the models, we portray the strategies investigation for contrast strategy. This systems were applied by [7], who presented a strategy for breaking down SSDs that utilizing another agreements based technique. Assume there are $p$ dynamic out of $\mathrm{m}$ components. The methodology as is depicted in [7] is as per the following.

\section{A: Discover all factor separates through}

$$
M=X^{T} Y,
$$

and $Y$ is the reaction and $X$ is the plan model lattice. At that point, ascertain the supreme qualities and arrange factors outright contracts

B: Start with $i=0$, then, use $p=N / 2$, where $\mathrm{N}$ is the number of trails.

C: Find the following

$$
u m l_{i}=\left|m_{k}\right|-t_{k-1, \alpha / 2} \sigma_{p}
$$

and

$$
l m l_{i}=-\left|m_{k}\right|+t_{k-1, \alpha / 2} \sigma_{p},
$$

where $t_{k-1, \alpha / 2}$ is the percent of the t- test.

D: Eliminate the greatest worth $\left|m_{k-i}\right|$ and subsequently set $i=i+1$.

E: Find $\sigma_{p}$ for the $\mathrm{p}$ biggest supreme differences utilizing the leftover qualities only.

F: From conditions(2) and (3), if the fluctuation in $\mathrm{E}$ is more modest than the difference that found before $\mathrm{C}$, go to Step $\mathrm{E}$ in any case stop, and close the dynamic components from the differentiations falling external the basic district

More details about this method can be found in [1]. In order to address these ethical concerns, the following example are taken.

\section{Data collection and Method}

\subsection{Written questionnaires and surveys}

The main technique used to recognize that included the consequences of study questions requested that members decide the spread of electronic games in Saudi society. Two of the most well-known strategies for veritable data were used :1/How many daily hours do you spend or spend around you playing electronic games. 2/understudy surveys were driven by spreading13-question reviews to understudies. The target masses was 200 individuals.

\subsection{Completing the trial and gathering infor- mation}

From setp 1, by then become familiar with the accomplishment levels for the focused on understudy utilizing the reasonable model. This is shown in Table 1, which explains the data accumulated. Information were introduced to backslide assessments and the agreements structure methodology, with the tracking down that the fundamental driver of spread of electronic games in Saudi society.

\subsection{Picking the example and ensuring in the event that it suits the various variables}

A pre-design consisting of 13 factors and 8 trials is selected. This design is considered in all the data that has been put in the previous steps and in case of obtaining the whole design is placed the value of the response and the number of the person who answered the questionnaire. The design chosen in the previous step is analysed using contrast method with supersaturated designs and regression methods. If the factors that we get from contrast method are the same as the regression method, these factors are the actual causes of electronic games in Saudi society. 
Table 1. Notes to be considered about the tables of information

\begin{tabular}{|c|c|c|}
\hline Factor & signal & Description \\
\hline $\begin{array}{l}\text { Some children or young people resort to these games in order to escape the real reality } \\
\text { to the virtual world }\end{array}$ & + & Yes \\
\hline $\begin{array}{l}\text { Insufficient awareness among parents of the dangers of these games, and excessive } \\
\text { pampering }\end{array}$ & + & Yes \\
\hline $\begin{array}{l}\text { Because of their constant preoccupation, some parents resort to such games in order } \\
\text { to get rid of the child's inconvenience }\end{array}$ & + & Yes \\
\hline Some games offer bonuses so children and young people continue to play long & + & $\begin{array}{l}\text { Yes } \\
\text { No }\end{array}$ \\
\hline $\begin{array}{l}\text { Love to brag and boast that their children have a lot of modern technological tools, } \\
\text { and their ability to deal with them quickly. }\end{array}$ & + & $\begin{array}{l}\text { Yes } \\
\text { No }\end{array}$ \\
\hline Children imitate a parent, there are some parents addicted to these games & $\begin{array}{l}+ \\
-\end{array}$ & $\begin{array}{l}\text { Yes } \\
\text { No }\end{array}$ \\
\hline $\begin{array}{l}\text { Lack of communication between parents and children, which makes the child resort } \\
\text { to such games in order to fill the gap suffered }\end{array}$ & + & $\begin{array}{l}\text { Yes } \\
\text { No }\end{array}$ \\
\hline $\begin{array}{l}\text { The financial return as a result of improved family income and the ability of children } \\
\text { and young people to acquire modern equipment and access to the Internet and play } \\
\text { these games }\end{array}$ & $\begin{array}{l}+ \\
-\end{array}$ & $\begin{array}{l}\text { Yes } \\
\text { No }\end{array}$ \\
\hline $\begin{array}{l}\text { The absence of the social role of social institutions such as clubs and school activities, } \\
\text { all of which occupied the time of students or youth, which led to resort to the practice } \\
\text { of electronic games to fill their free time }\end{array}$ & $\begin{array}{l}+ \\
-\end{array}$ & $\begin{array}{l}\text { Yes } \\
\text { No }\end{array}$ \\
\hline The gap between generation and generation increased significantly & + & $\begin{array}{l}\text { Yes } \\
\text { No }\end{array}$ \\
\hline Blaming one parent for the other & + & $\begin{array}{l}\text { Yes } \\
\text { No }\end{array}$ \\
\hline Impressed, admired and emulated by foreign cultures & + & $\begin{array}{l}\text { Yes } \\
\text { No }\end{array}$ \\
\hline Lack of media role on awareness of the dangers of these games & $\begin{array}{l}+ \\
+ \\
-\end{array}$ & $\begin{array}{l}\text { Yes } \\
\text { No }\end{array}$ \\
\hline Y(Response) & Number & $\begin{array}{l}\text { The number } \\
\text { of hours to } \\
\text { spend playing } \\
\text { electronic } \\
\text { games }\end{array}$ \\
\hline
\end{tabular}

Table 2. Supersaturated design for Example 1.

\begin{tabular}{|c|c|c|c|c|c|c|c|c|c|c|c|c|c|c|}
\hline Run & $x_{1}$ & $x_{2}$ & $x_{3}$ & $x_{4}$ & $x_{5}$ & $x_{6}$ & $x_{7}$ & $x_{8}$ & $x_{9}$ & $x_{10}$ & $x_{11}$ & $x_{12}$ & $x_{13}$ & $\mathrm{Y}$ \\
\hline 1 & -1 & 1 & 1 & 1 & -1 & 1 & 1 & 1 & 1 & 1 & 1 & -1 & -1 & 5 \\
2 & -1 & 1 & 1 & 1 & 1 & 1 & -1 & -1 & 1 & 1 & -1 & -1 & -1 & 1 \\
3 & -1 & 1 & 1 & 1 & 1 & 1 & 1 & 1 & 1 & 1 & 1 & 1 & 1 & 5 \\
4 & 1 & 1 & 1 & -1 & -1 & 1 & 1 & -1 & 1 & 1 & 1 & 1 & 1 & 15 \\
5 & 1 & -1 & -1 & 1 & -1 & -1 & -1 & -1 & 1 & -1 & -1 & 1 & -1 & 5 \\
6 & -1 & -1 & 1 & 1 & 1 & -1 & -1 & 1 & 1 & 1 & 1 & 1 & -1 & 0.3 \\
7 & -1 & 1 & 1 & 1 & 1 & 1 & 1 & 1 & 1 & 1 & 1 & 1 & -1 & 3 \\
8 & 1 & 1 & 1 & 1 & 1 & 1 & 1 & -1 & 1 & -1 & -1 & 1 & 1 & 16 \\
\hline
\end{tabular}


Table 3. Arranged supreme differentiations esteems for example 1 .

\begin{tabular}{ccccccccc}
\hline$j$ & 1 & 2 & 3 & 4 & 5 & 6 & 7 & 8 \\
$x_{n}$ & $x_{9}$ & $x_{3}$ & $x_{2}$ & $x_{6}$ & $x_{12}$ & $x_{7}$ & $x_{8}$ & $x_{1}$ \\
$\mid c_{(j) \mid}$ & 50.3 & 40.3 & 39.7 & 39.7 & 38.3 & 37.7 & 23.7 & 21.7 \\
\hline$j$ & 9 & 10 & 11 & 12 & 13 & & & \\
$x_{n}$ & $x_{13}$ & $x_{4}$ & $x_{10}$ & $x_{11}$ & $x_{5}$ & & & \\
$\left|c_{(j)}\right|$ & 21.7 & 20.3 & 8.3 & 6.03 & 0.3 & & & \\
\hline
\end{tabular}

Table 4. Step by step figurings for the examination model 1

\begin{tabular}{ccccc}
\hline$i$ & $\sigma_{i}^{2}$ & $u m l_{i}$ & $l m l_{i}$ & $\sigma_{i}^{2}$ more than $\sigma_{i-1}^{2}$ \\
\hline 0 & 27.12 & 38.95 & -38.95 & \\
1 & 0.72 & 38.43 & -38.43 & No \\
2 & 1.02 & 37.44 & -37.44 & Yes
\end{tabular}

\section{Data Analysis}

The performance of contrast method with supersaturated designs methods is assessed in terms of their ability to define the active value. More details about this method can be found in [1]. In order to address these ethical concerns, the following example are taken.

\section{Example 1.}

In this example, we assume $n=13$ that shown in Table 2. The aforementioned analysis methods were performed respectively. We portray the systems examination for supersaturated design in Table 2. All factor contrasts calculate the absolutes using Equation 1, and sort these valuesin Table 3. Then, start with $i=0$ and figure the difference of the p biggest total agreements using $p=N / 2$, where $\mathrm{N}$ is the number of trials. The result is in Table 4.

We see that $\sigma_{2}^{2}$ is more than $\sigma_{1}^{2}$, and subsequently we pause and track down the dynamic components. The final values for A are:

$$
u m l_{i}=38.43, \quad l m l_{i}=-38.43 \quad \text { and } \quad \sigma_{1}^{2}=0.72 .
$$

Accordingly, there are actives factors outside the basic area: $x_{9}, x_{3}, x_{2}$ and $x_{6}$. Examination of these information (Forward determination) with programming bundle SPSS, uncovers as dynamic factors $x_{1}$ and $x_{3}$, an expected straight model is:

$$
y=3.930+6.320 x_{1}+5.320 x_{3}+\varepsilon .
$$

Investigation of these information (utilizing regression) with programming bundle SPSS, uncovers as dynamic factors $x_{1}$, $x_{3}$ and $x_{7}$, an expected direct model is:

$$
y=4.677+5.58 x_{1}+3.40 x_{3}+1.84 x_{7}+\varepsilon .
$$

The robust contrast method result in four active factors $x_{9}, x_{3}, x_{2}$ and $x_{6}$ and the regression analysis method result in three active factors $x_{1}, x_{3}$ and $x_{7}$. Thus, there is a single active factor $x_{3}$ (because of their constant preoccupation, some parents resort to such games in order to get rid of the child's inconvenience) with a linear contribution.
Example 2. In this example, the same procedures used in example 1 with $n=13$, analysis for contrast method depict in Table 5.

The sorted absolute contrast values are depicted in sort these values in Table 6 .

The resulting variance of the $p$ largest absolute contracts is shown in Table 7.

The detecting of the active factors were stopped as $\sigma_{1}^{2}$ is more than $\sigma_{0}^{2}$. The final values for $\mathrm{A}$ are:

$$
u m l_{i}=56.28, \quad l m l_{i}=-56.28 \quad \text { and } \quad \sigma_{0}^{2}=16 .
$$

This result in five actives factors outside the critical region: $x_{2}, x_{7}, x_{9}, x_{2}$ and $x_{10}$. The active variable based on analysis in this case is $x_{3}$ with the following estimated linear model:

$$
y=12.35-5.64 x_{3}+\varepsilon .
$$

For convenience, regression method also used to detect the active variable, which result in $x_{3}$ as active variable with linear model:

$$
y=12.35-5.64 x_{3}+\varepsilon .
$$

Based on above analysis, we conclude that there is no an active factor with a linear contribution.

Example 3. The supersaturated design for this example are depicted in Table 8.

The sorted absolute contrast values are shown in Table 9.

Table 10 shown the result from calculating the variance of the p largest absolute contracts.

The result from calculating the lower and upper limits on critical region are:

$$
u m l_{i}=30.37, \quad l m l_{i}=-30.37 \quad \text { and } \quad \sigma_{1}^{2}=12,
$$

which show that there are actives factors outside the basic district: $x_{13}, x_{5}, x_{2}$ and $x_{9}$. 
Table 5. Supersaturated design for Example 2.

\begin{tabular}{|c|c|c|c|c|c|c|c|c|c|c|c|c|c|c|}
\hline Run & $x_{1}$ & $x_{2}$ & $x_{3}$ & $x_{4}$ & $x_{5}$ & $x_{6}$ & $x_{7}$ & $x_{8}$ & $x_{9}$ & $x_{10}$ & $x_{11}$ & $x_{12}$ & $x_{13}$ & $\mathrm{Y}$ \\
\hline 1 & 1 & 1 & 1 & 1 & 1 & 1 & 1 & 1 & 1 & 1 & 1 & 1 & 1 & 4 \\
2 & 1 & 1 & 1 & -1 & -1 & 1 & 1 & 1 & 1 & 1 & 1 & -1 & 1 & 9 \\
3 & 1 & 1 & 1 & 1 & -1 & -1 & 1 & -1 & 1 & 1 & 1 & 1 & -1 & 6 \\
4 & 1 & 1 & -1 & -1 & 1 & 1 & 1 & -1 & 1 & 1 & -1 & -1 & 1 & 18 \\
5 & 1 & -1 & 1 & -1 & -1 & -1 & 1 & -1 & 1 & -1 & -1 & -1 & -1 & 4 \\
6 & 1 & 1 & 1 & 1 & 1 & 1 & 1 & 1 & 1 & 1 & 1 & 1 & 1 & 4 \\
7 & 1 & 1 & 1 & 1 & 1 & 1 & 1 & -1 & 1 & 1 & 1 & 1 & 1 & 8 \\
8 & 1 & 1 & 1 & 1 & 1 & 1 & 1 & 1 & 1 & 1 & 1 & 1 & 1 & 12 \\
\hline
\end{tabular}

Table 6. Arranged supreme differentiations esteems for example 2 .

\begin{tabular}{ccccccccc}
\hline$j$ & 1 & 2 & 3 & 4 & 5 & 6 & 7 & 8 \\
$x_{n}$ & $x_{2}$ & $x_{7}$ & $x_{9}$ & $x_{2}$ & $x_{10}$ & $x_{6}$ & $x_{13}$ & $x_{3}$ \\
$\left|c_{(j)}\right|$ & 65 & 65 & 65 & 57 & 57 & 45 & 45 & 29 \\
\hline$j$ & 9 & 10 & 11 & 12 & 13 & & & \\
$x_{n}$ & $x_{5}$ & $x_{11}$ & $x_{8}$ & $x_{4}$ & $x_{12}$ & & & \\
$\left.\mid c_{(} j\right) \mid$ & 27 & 21 & 7 & 3 & 3 & & & \\
\hline
\end{tabular}

Table 7. Figurings for the examination model 2.

\begin{tabular}{ccccc}
\hline$i$ & $\sigma_{i}^{2}$ & $u m l_{i}$ & $\operatorname{lm} l_{i}$ & $\sigma_{i}^{2}$ more than $\sigma_{i-1}^{2}$ \\
\hline 0 & 16 & 56.28 & -56.28 & \\
1 & 21.33 & 54.83 & -54.83 & Yes
\end{tabular}

Table 8. Supersaturated design for Example 3.

\begin{tabular}{|c|c|c|c|c|c|c|c|c|c|c|c|c|c|c|}
\hline Run & $x_{1}$ & $x_{2}$ & $x_{3}$ & $x_{4}$ & $x_{5}$ & $x_{6}$ & $x_{7}$ & $x_{8}$ & $x_{9}$ & $x_{10}$ & $x_{11}$ & $x_{12}$ & $x_{13}$ & $\mathrm{Y}$ \\
\hline 1 & 1 & 1 & 1 & -1 & -1 & 1 & 1 & -1 & 1 & -1 & 1 & 1 & 1 & 3 \\
2 & 1 & 1 & 1 & -1 & -1 & 1 & 1 & -1 & 1 & -1 & 1 & 1 & 1 & 3 \\
3 & 1 & 1 & 1 & -1 & -1 & 1 & 1 & -1 & 1 & -1 & 1 & 1 & 1 & 3 \\
4 & 1 & 1 & 1 & 1 & 1 & -1 & 1 & 1 & 1 & 1 & 1 & -1 & 1 & 3 \\
5 & -1 & -1 & -1 & -1 & -1 & -1 & -1 & -1 & -1 & -1 & 1 & -1 & 1 & 6 \\
6 & -1 & 1 & -1 & 1 & -1 & 1 & 1 & -1 & 1 & 1 & -1 & 1 & 1 & 4 \\
7 & -1 & 1 & 1 & 1 & -1 & -1 & -1 & 1 & 1 & -1 & -1 & -1 & 1 & 10 \\
8 & -1 & 1 & 1 & 1 & -1 & -1 & -1 & 1 & 1 & -1 & -1 & -1 & 1 & 12 \\
\hline
\end{tabular}

Table 9. Arranged supreme differentiations esteems for example 3 .

\begin{tabular}{ccccccccc}
\hline$j$ & 1 & 2 & 3 & 4 & 5 & 6 & 7 & 8 \\
$x_{n}$ & $x_{13}$ & $x_{5}$ & $x_{2}$ & $x_{9}$ & $x_{10}$ & $x_{3}$ & $x_{1}$ & $x_{6}$ \\
$\left|c_{(j)}\right|$ & 44 & 38 & 32 & 32 & 30 & 24 & 20 & 18 \\
\hline$j$ & 9 & 10 & 11 & 12 & 13 & & & \\
$x_{n}$ & $x_{12}$ & $x_{4}$ & $x_{7}$ & $x_{11}$ & $x_{8}$ & & & \\
$\mid c_{(j) \mid}$ & 18 & 14 & 12 & 8 & 6 & & & \\
\hline
\end{tabular}

Investigation of these information utilizing Forward determination uncovers that the dynamic factors are $x_{2}$ and $x_{7}$ and assessed direct model is:

$$
y=4.600+2.500 x_{2}-3.900 x_{7}+\varepsilon .
$$

We then perform regression analysis, which result in two active variables $x_{2}, x_{7}$. The obtained linear model is:

$y=4.600+2.500 x_{2}-3.900 x_{7}+\varepsilon$. The robust contrast method result in four active factors $x_{13}, x_{5}, x_{2}$ and $x_{9}$ while the regression analysis method gives two active factors 
Table 10. Figurings for the examination model 3 .

\begin{tabular}{ccccc}
\hline$i$ & $\sigma_{i}^{2}$ & $u m l_{i}$ & lml & $\sigma_{i}^{2}$ more than $\sigma_{i-1}^{2}$ \\
\hline 0 & 33 & 31.48 & -31.48 & \\
1 & 12 & 30.37 & -30.37 & No \\
2 & 14.33 & 23.56 & -23.56 & Yes
\end{tabular}

Table 11. Supersaturated design for Example 4.

\begin{tabular}{|c|c|c|c|c|c|c|c|c|c|c|c|c|c|c|}
\hline Run & $x_{1}$ & $x_{2}$ & $x_{3}$ & $x_{4}$ & $x_{5}$ & $x_{6}$ & $x_{7}$ & $x_{8}$ & $x_{9}$ & $x_{10}$ & $x_{11}$ & $x_{12}$ & $x_{13}$ & $\mathrm{Y}$ \\
\hline 1 & -1 & 1 & 1 & 1 & -1 & 1 & -1 & -1 & 1 & 1 & 1 & -1 & 1 & 6 \\
2 & 1 & 1 & 1 & 1 & 1 & 1 & 1 & 1 & 1 & 1 & 1 & 1 & -1 & 24 \\
3 & 1 & 1 & 1 & 1 & 1 & -1 & 1 & 1 & 1 & 1 & 1 & 1 & 1 & 3 \\
4 & 1 & 1 & 1 & 1 & 1 & -1 & 1 & -1 & 1 & 1 & -1 & -1 & 1 & 10 \\
5 & 1 & 1 & 1 & 1 & 1 & 1 & 1 & 1 & 1 & 1 & 1 & -1 & 1 & 3 \\
6 & 1 & 1 & 1 & 1 & -1 & -1 & 1 & -1 & 1 & 1 & 1 & -1 & 1 & 0 \\
7 & 1 & 1 & 1 & 1 & 1 & 1 & 1 & 1 & 1 & 1 & 1 & 1 & 1 & 2 \\
8 & 1 & -1 & 1 & 1 & 1 & -1 & 1 & -1 & 1 & -1 & 1 & 1 & 1 & 3 \\
\hline
\end{tabular}

Table 12. Arranged supreme differentiations esteems for example 4 .

\begin{tabular}{ccccccccc}
\hline$j$ & 1 & 2 & 3 & 4 & 5 & 6 & 7 & 8 \\
$x_{n}$ & $x_{3}$ & $x_{4}$ & $x_{9}$ & $x_{2}$ & $x_{10}$ & $x_{1}$ & $x_{5}$ & $x_{7}$ \\
$\left|c_{(j)}\right|$ & 51 & 51 & 51 & 45 & 45 & 39 & 39 & 39 \\
\hline$j$ & 9 & 10 & 11 & 12 & 13 & & & \\
$x_{n}$ & $x_{11}$ & $x_{6}$ & $x_{8}$ & $x_{12}$ & $x_{13}$ & & & \\
$\left|c_{(j)}\right|$ & 31 & 19 & 13 & 13 & 3 & & & \\
\hline
\end{tabular}

Table 13. Figurings for the examination model 4 .

\begin{tabular}{ccccc}
\hline$i$ & $\sigma_{i}^{2}$ & $u m l_{i}$ & $l m l_{i}$ & $\sigma_{i}^{2}$ more than $\sigma_{i-1}^{2}$ \\
\hline 0 & 9 & 44.46 & -44.46 & \\
1 & 12 & 43.37 & -43.37 & Yes
\end{tabular}

$x_{2}$ and $x_{7}$. In this case, there is only one active factor $x_{2}$ (which is insufficient awareness among parents of the dangers of these games, and excessive pampering) with a linear contribution.

\section{Example 4.}

The results from performing the same procedure are shown in Table 11.

At that point we discover all factor differences from condtion 1, compute the absolutes and arrange these qualities. The outcome is appeared in Table 12.

Start with $i=0$ and figure the change of the $\mathrm{p}$ biggest supreme agreements use $p=N / 2$, where $\mathrm{N}$ is the number of trials. The outcome is appeared in Table 13.

We see that $\sigma_{1}^{2}$ is more than $\sigma_{0}^{2}$, and consequently we pause and track down the dynamic elements. The last qualities for A are

$$
u m l_{i}=44.46, \quad l m l_{i}=-44.46 \quad \text { and } \quad \sigma_{0}^{2}=9 .
$$

cordingly, there are actives factors outside the basic locale: $x_{3}, x_{4}, x_{9}, x_{2}$ and $x_{10}$. Investigation of these information dependent on forward choice is bring about two dynamic factors $x_{11}$ and $x_{13}$. The assessed straight model:

$$
y=17-3.58 x_{11}-10.58 x_{13}+\varepsilon .
$$

Analysis of these information utilizing relapse bring about two dynamic elements $x_{11}$ and $x_{13}$, the acquired direct model:

$$
y=17-3.58 x_{11}-10.58 x_{13}+\varepsilon .
$$

In view of the above examination, we infer that there is no dynamic factor with a direct commitment.

\section{Conclusions}

This paper examined the actual causes that led to the spread of electronic games in Saudi society using contrast method analysis and the regression analysis. A pre-design consisting of 13 factors and 8 trials is selected to performance of contrast method with supersaturated designs methods is assessed in terms of their ability to define the active value. This examples illustrates that supersaturated design and regression model method are very effective for screening effect. The result show that the factor (because of their constant preoccupation, some parents resort to such games in order to get rid of the child's inconvenience and insufficient awareness among parents of the dangers of these games), and excessive pampering are the factors that led to the spread of electronic games in Saudi society statistically.On this premise, it is suggested that Saudi government experts build up an operational arrangement to consider these causes to make moves. In future examinations, no new investigations address the outer natural viewpoints that could impact gaming among people, and thus further exploration 
is needed in this field. Moreover, there is a prerequisite for more examination contemplates that address various pieces of electronic games, for instance, the degree of this wonder with three levles $(+, 0,-)$.

\section{Abbreviations:}

SPSS: Statistical package for social sciences

\subsection{Ethics approval and consent to participate}

Not applicable

\subsection{Availability of data and material}

The data supports the finding of this study are available within the article and its supplementary material.

\subsection{Competing interests}

Not applicable

\subsection{Funding}

Not applicable

\section{REFERENCES}

[1] T Alanazi. Construction and analysis of experimental designs. 2018.

[2] Mohammed A Alqurashi and Mia K Williams. The teachers' experiences with video games play in saudi arabia. pages 58-84, 2017.

[3] Scott D Beattie, Duncan K H Fong, and Dennis K J Lin. A two-stage bayesian model selection strategy for supersaturated designs. Technometrics, 44(1):55-63, 2002.

[4] Kathleen HV Booth and David R Cox. Some systematic supersaturated designs. Technometrics, 4(4):489-495, 1962.
[5] Dursun A Bulutoglu, Ching-Shui Cheng, et al. Construction of e (s2)-optimal supersaturated designs. The Annals of Statistics, 32(4):1662-1678, 2004.

[6] Jiahua Chen and Dennis KJ Lin. On the identifiability of a supersaturated design. Journal of Statistical Planning and Inference, 72(1-2):99-107, 1998.

[7] C Koukouvinos and S Stylianou. A method for analyzing supersaturated designs. Communications in Statistics-Simulation and Computation ${ }^{\circledR}, 34(4): 929$ 937, 2005.

[8] Runze Li and Dennis KJ Lin. Data analysis in supersaturated designs. Statistics \& Probability Letters, 59(2):135-144, 2002.

[9] Dennis KJ Lin. A new class of supersaturated designs. Technometrics, 35(1):28-31, 1993.

[10] Yufeng Liu, Shiling Ruan, and Angela M Dean. Construction and analysis of es2 efficient supersaturated designs. Journal of Statistical Planning and Inference, 137(5):1516-1529, 2007.

[11] Xuan Lu and Xi Wu. A strategy of searching active factors in supersaturated screening experiments. Journal of Quality Technology, 36(4):392-399, 2004.

[12] FE Satterthwaite. Random balance experimentation. Technometrics, 1(2):111-137, 1959.

[13] Peter H Westfall, S Stanley Young, and Dennis KJ Lin. Forward selection error control in the analysis of supersaturated designs. Statistica Sinica, pages 101-117, 1998.

[14] Hongquan Xu, CFJ Wu, et al. Construction of optimal multi-level supersaturated designs. The Annals of Statistics, 33(6):2811-2836, 2005.

[15] Shu Yamada and Dennis KJ Lin. Three-level supersaturated designs. Statistics \& probability letters, 45(1):3139, 1999. 